\title{
Thermochemical stability and nonstoichiometry of erbia-stabilized bismuth oxide
}

\author{
H. Kruidhof, H.J.M. Bouwmeester ', K.J. de Vries, P.J. Gellings and A.J. Burggraaf \\ Laboratory for Inorganic Chemistry, Materials Science and Catalysis, Department of Chemical Technology, University of Twente, \\ PO Box 217, 7500 AE Enschede, The Netherlands
}

Received 28 September 1990; accepted for publication 10 September 1991

\begin{abstract}
A phase study has been performed of high oxygen ion conducting erbia-stabilized bismuth oxide $(1-x) \mathrm{Bi}_{2} \mathrm{O}_{3} \cdot x \mathrm{Er}_{2} \mathrm{O}_{3}(\mathrm{BE} 100 \times)$ using thermal analysis and X-ray powder diffraction. Investigation of the effect of a long-time $(500 \mathrm{~h})$ anneal of samples at $650^{\circ} \mathrm{C}$ in air revealed that the minimum amount of erbia nceded to stabilize the high-temperature cubic $\delta-\mathrm{Bi}_{2} \mathrm{O}_{3}$ phase is 27.5 at $\%$. This boundary value is much larger than the one usually reported in literature where the sluggishenss of the transformation from cubic to hexagonal at high $\mathrm{Bi}$ contents is not taken into account. Changes in nonstoichiometry of solid solutions $\mathrm{Bi}_{2-2 x} \mathrm{Er}_{2 x} \mathrm{O}_{3+\delta}$ between $550^{\circ} \mathrm{C}$ and $850^{\circ} \mathrm{C}$ upon varying the ambient oxygen partial pressure are minimal for samples with 27.5 at $\%$ erbia, increasing with increasing erbia content. The parameter $\delta$ in pure oxygen increases from 0.0044 for BE27.5 to 0.022 for BE50 taking the composition in nitrogen $\left(P_{\mathrm{O}_{2}} \approx 10^{-4} \mathrm{~atm}\right)$ as stoichiometric reference $(\delta=0)$.
\end{abstract}

\section{INTRODUCTION}

Erbia and yttria stabilized phases of cubic $\delta-\mathrm{Bi}_{2} \mathrm{O}_{3}$ are among the best oxygen ion conductors known [17].

Phase analysis by Watanabe and Kikuchi [8] showed a fast polymorphic transition from hexagonal (rhombohedral) to the high-temperature cubic fcc structure related to the $\delta$-phase in the system $(1-x) \mathrm{Bi}_{2} \mathrm{O}_{3} \times \mathrm{XY}_{2} \mathrm{O}_{3}$ (BY100x) at about $720^{\circ} \mathrm{C}$. Since the reverse transition was. found to be very slow the cubic phase is easily obtained by quenching. The homogeneity region of the hexagonal phase as obtained by accurate determination of the structural parameters using $X$-ray diffraction is relatively narrow and ranges from about $x=0.215$ to $x=0.235$. Above and below this region two-phase regions will appear.

In a previous paper [9] we reported the minimum amount of yttria necessary to stabilize the cubic phase in (1-x) $\mathrm{Bi}_{2} \mathrm{O}_{3} \times \mathrm{Y}_{2} \mathrm{O}_{3}$ even after annealing over long periods $(>500 \mathrm{~h})$ at $650^{\circ} \mathrm{C}$ to be 32 at\%, which is much larger than found in literature where the cubic to hexagonal phase transition is not taken into account $[4,6]$.

The operating temperature of stabilized bismuth oxides as solid electrolyte is between $400^{\circ} \mathrm{C}$ and $750^{\circ} \mathrm{C}$. Structural instabilities may limit the prospects of using them in devices such as fuel cells, sensors etc., of which the life-span should be as long as possible. As measured for yttria-stabilized bismuth oxide the cubic to hexagonal phase transition has a detrimental effect on the ionic conductivity $[4,5]$. Determination of the minimum amount of dopant oxide to stabilize the cubic phase is of importance, since the ionic conductivity is known to decrease with increasing dopant concentration $[2,4]$.

According to literature the cubic phase in $(1-\mathrm{x}) \mathrm{Bi}_{2} \mathrm{O}_{3}, \mathrm{xEr}_{2} \mathrm{O}_{3}$ (BE100x) is stabilized between 17.5 and 45 mol.\% erbia [2,10]. However, as described previously [11] the cubic phase gradually transforms into a hexagonal one during annealing of a sample of composition BE25 at $650^{\circ} \mathrm{C}$. Therefore we started a phase study on the system $\mathrm{Bi}_{2} \mathrm{O}_{3}-\mathrm{Er}_{2} \mathrm{O}_{3}$ using combined TG, DTA and X-ray measurements of which the results are presented in this paper.

\footnotetext{
'To whom all correspondence should be addressed.
} 


\section{EXPERIMENTAL PROCEDURES}

Solid solutions of bismuth oxide containing $20-50$ mol\% erbia were prepared by the coprecipitation technique described elsewhere [12]. High purity raw materials (99.9\%) were used to obtain samples of various compositions. After synthesis and drying the samples were calcined at $760^{\circ} \mathrm{C}$ to complete the solid solution formation. The effect of calcination on solid solution formation was investigated by applying different calcination times, $3 \mathrm{~h}, 8 \mathrm{~h}$ and $20 \mathrm{~h}$, respectively. Powders thus obtained were annealed in air at $650^{\circ} \mathrm{C}$ during $500 \mathrm{~h}$.

Structure analysis was performed before as well as after the anneal by X-ray powder diffraction (XRD) using $\mathrm{Cu} K \boldsymbol{\alpha}$ radiation. Differential thermal analysis (DTA) and thermogravimetric analysis (TGA) were both performed on a Du Pont 990 model thermal analyzer.

TGA was performed on powder samples calcined during 8h. A small piece of a sintered dense disk of BE25 was also measured to investigate whether weight changes originate from surface and/or bulk processes. The relative density of the dense ceramic was more than $\mathbf{9 8 \%}$ as determined on the basis of the cell parameters from XRD. The surface area was found to be about $10^{-4}$ times smaller than that of a powder sample with equal weight.

In the TGA experiments the sample was first equilibrated in nitrogen $\left(\mathrm{pO}_{2} \approx 10^{-4} \mathrm{~atm}\right)$ at $850^{\circ} \mathrm{C}$. The atmosphere was then changed from nitrogen to pure oxygen. After reaching constant weight (no weight changes within $1 \mathrm{~h}$ ) the sample was cooled under oxygen to $420^{\circ} \mathrm{C}$. This temperature was maintained until no further weight change was observed $(\approx 20 \mathrm{~h})$. Finally, the atmosphere was changed to nitrogen again and the temperature raised to $850^{\circ} \mathrm{C}$. Heating and cooling rates were $10^{\circ} \mathrm{C} / \mathrm{min}$. Gas flow rates were about $15 \mathrm{ml} / \mathrm{min}$.

\section{RESULTS AND DISCUSSION}

\subsection{X-ray diffraction}

Before annealing at $650^{\circ} \mathrm{C}$ all samples within the range of composition BE20 - BE35 possess the cubic structure as shown by X-ray analysis and DTA measurements (see below).
After annealing at $650^{\circ} \mathrm{C}$ during $500 \mathrm{~h}$ samples containing less then 27.5 at\% $\mathrm{Er}$ (BE27.5) showed the presence of an additional hexagonal phase. These observations agree with earlier results described elsewhere [11]. From peak intensity changes it is concluded that the amount of hexagonal phase present decreases strongly with increasing erbia content and with increasing calcination time.

The hexagonal phase could not be observed in annealed samples with erbia contents equal to or larger than 27.5 at\%. Diffraction lines in powder patterns of samples calcined during $3 \mathrm{~h}$ at $760^{\circ} \mathrm{C}$ were generally broadened in comparison to those in powder patterns of samples calcined during $8 \mathrm{~h}$ or $20 \mathrm{~h}$. The anneal treatment of the former samples even led to a further broadening. This may indicate poor homogeneity upon calcination. No broadening of the diffraction lines by the anneal at $650^{\circ} \mathrm{C}$ was observed for samples calcined during $8 \mathrm{~h}$ or $20 \mathrm{~h}$. Powder patterns of samples with 27.5 at\% erbia already showed sharp diffraction lines after $3 \mathrm{~h}$ calcination.

\subsection{Differential thermal analysis}

The hexagonal to cubic phase transition is fast and accompanied by a large endothermic heat effect $[9,11,13]$. For this reason DTA can be applied to trace the presence of the hexagonal phase. Prior to annealing no heat effects were observed during DTA measurements, indicating all samples to have the cubic structure.

After annealing in air at $650^{\circ} \mathrm{C}$ during $500 \mathrm{~h}$ samples containing less than 27.5 at\% erbia showed two consecutive endothermic heat effects in DTA (Fig. 1). The corresponding temperatures depend on composition as shown in Fig. 2.

The phase transformation from hexagonal to cubic in the system $\mathrm{Bi}_{2} \mathrm{O}_{3}-\mathrm{Y}_{2} \mathrm{O}_{3}$ is accompanied by a single endothermic heat effect [9]. The present results indicate that the corresponding phase transformation in $\mathrm{Bi}_{2} \mathrm{O}_{3}-\mathrm{Er}_{2} \mathrm{O}_{3}$ proceeds in two steps. It is suggested that ordering processes might play a role.

As shown in Fig. 3 the magnitude of the heat effects decreases with increasing erbia content becoming zero for BE27.5. This implies that the amount of hexagonal phase introduced by the anneal at $650^{\circ} \mathrm{C}$ decreases with increasing erbia content. A similar behaviour was found for yttria stabilized $\delta$ bismuth oxide [9]. 


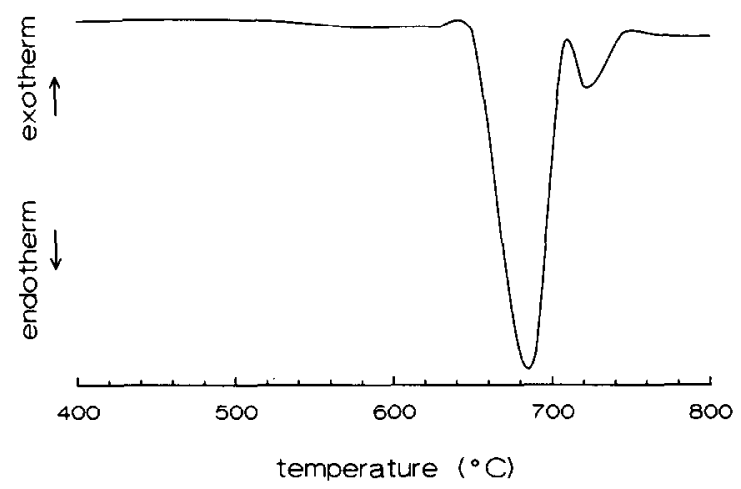

Fig.1 DTA heating curve of annealed BE20 showing the hexagonal to cubic phase transformation to proceed in two steps.

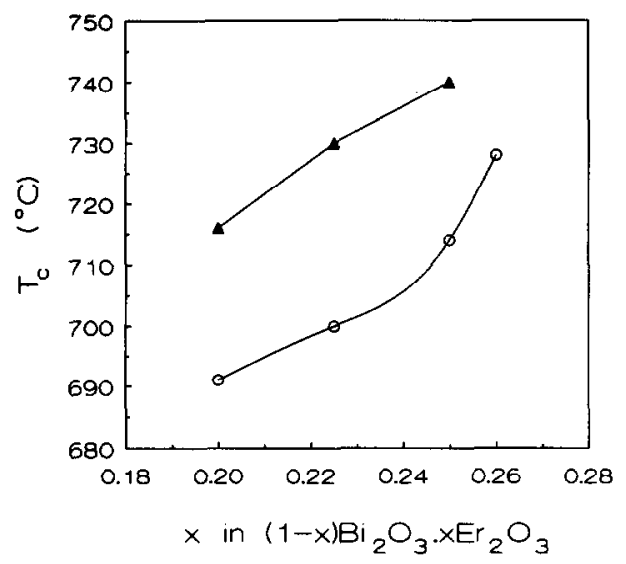

Fig.2 Compositional dependence of the transition temperature, $T_{c}$, observed in DTA of samples $(1-\mathrm{x}) \mathrm{Bi}_{2} \mathrm{O}_{3} \cdot \mathrm{xEr}_{2} \mathrm{O}_{3}$ calcined during $8 \mathrm{~h}$ and subsequently annealed in air at $650^{\circ} \mathrm{C}$ during $500 \mathrm{~h}$. Lowest and highest transition temperature as shown in Fig. 1 are denoted by symbols (0) and (4), respectively.

No heat effects were observed in DTA of annealed samples in the range of BE27.5 - BE35 calcined during $8 \mathrm{~h}$ or longer. If, however, the calcination time was only $3 \mathrm{~h}$ a single endothermic heat effect was observed. This is attributed to slow kinetics during calcination. As noted before no heat effect was observed in these samples prior to annealing. The calcination time of $3 \mathrm{~h}$ probably is too short and may lead to an inhomogeneous product.

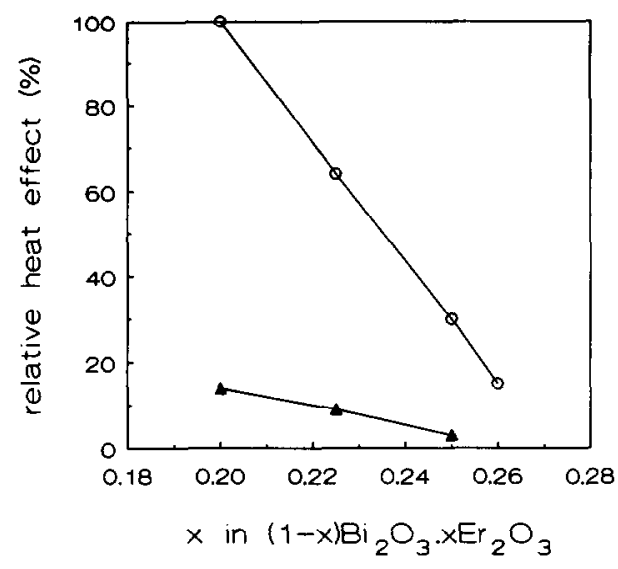

Fig.3 Compositional dependence of heat effects of transitions observed in DTA of samples $(1-\mathrm{x}) \mathrm{Bi}_{2} \mathrm{O}_{3} \cdot \mathrm{xEr}_{2} \mathrm{O}_{3}$ calcined during $8 \mathrm{~h}$ and subsequently annealed in air at $650^{\circ} \mathrm{C}$ during $500 \mathrm{~h}$. Values given are relative to BE20. Lowest and highest transition temperature as shown in Fig. 1 are denoted by symbols (o) and ( 4$)$, respectively.

The combined results of DTA and X-ray analysis of samples calcined during $3 \mathrm{~h}$ suggest the growth of hexagonal domains into larger ones during the longtime anneal at $650^{\circ} \mathrm{C}$.

\subsection{Thermogravimetric analysis}

Typical TGA data of powder samples as measured between $420^{\circ} \mathrm{C}$ and $850^{\circ} \mathrm{C}$ are shown in Fig. 4. Points (a) through (d) were monitored until the weight remained constant during at least $1 \mathrm{~h}$.

At $850^{\circ} \mathrm{C}$ a rapid oxygen uptake occurs upon changing the ambient gas atmosphere from nitrogen to pure oxygen $(a \rightarrow b$ in Fig. 4). Cooling results in a further weight increase between $550^{\circ} \mathrm{C}$ and $420^{\circ} \mathrm{C}$ $\left(c \rightarrow d^{\prime}\right)$. The equilibration under oxygen at $420^{\circ} \mathrm{C}$ $\left(d^{\prime} \rightarrow d\right)$ is a slow process and takes about $20 \mathrm{~h}$. The last mentioned temperature was selected because preliminary experiments showed that the maximum uptake of oxygen occurs at this temperature. Upon changing the gas atmosphere from oxygen to nitrogen again and increasing the temperature a weight loss is observed between $420^{\circ} \mathrm{C}$ and $550^{\circ} \mathrm{C}$. Between $550^{\circ}$ and $850^{\circ} \mathrm{C}$ no further weight losses are observed. At $850^{\circ} \mathrm{C}$ point (a) is reached again.

These results indicate that erbia stabilized bismuth 


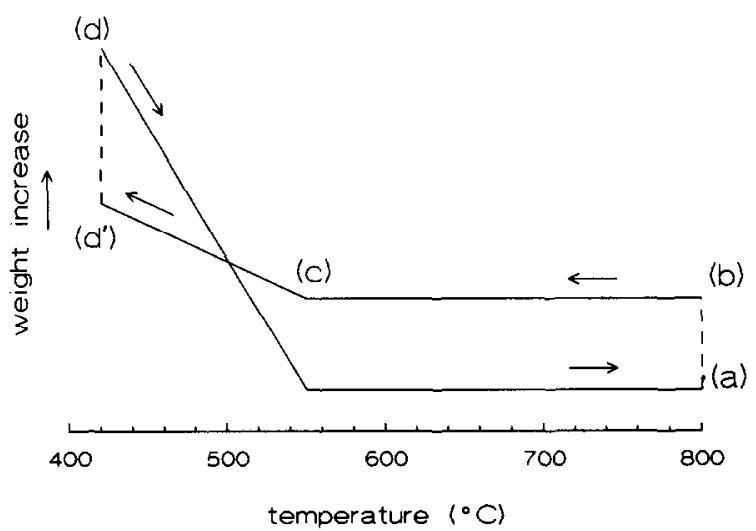

Fig.4 Schematic TGA diagram of a sample $(1-x) \mathrm{Bi}_{2} \mathrm{O}_{3} \times \mathrm{xEr}_{2} \mathrm{O}_{3}$ upon heating in nitrogen gas and cooling in pure oxygen as denoted by arrows. For explanation, see text.

oxide reversibly exchanges oxygen with the ambient gas atmosphere. The oxygen exchange is a function of temperature and oxygen partial pressure.

The results of TGA measurements of dense ceramics above $550^{\circ} \mathrm{C}$ are equal to those of powders. On the contrary the oxygen uptake by the dense ceramics is significantly less than that of powders below $550^{\circ} \mathrm{C}$. From these observations it is concluded that weight changes are only due to bulk processes above $550^{\circ} \mathrm{C}$, while below this temperature adsorption of oxygen on the surface of the material is partly responsible.

In Fig. 5 the departure from stoichiometry, $\delta$, in pure oxygen is plotted versus the compositional parameter $x$. This departure is calculated from the weight increase [W(b)-W(a)] according to equation

$$
\delta=\frac{M_{s}}{\bar{M}_{0}} \times \frac{[W(b)-W(a)]}{W(a)}
$$

where $M_{S}$ is the mean molar weight of the solid solution and $\mathrm{M}_{\mathrm{O}}$ the molar weight of atomic oxygen. The composition, explicitly written as $\mathrm{Bi}_{2-2 x} \mathrm{Er}_{2 x} \mathrm{O}_{3+\delta}$ in nitrogen is taken as stoichiometric. reference $(\delta=$ $0)$. From Fig. 5 it is seen that above composition BE28, $\delta$ increases with erbia content to 0.022 for BE50. Note that the composition BE28 at which the anomaly occurs in Fig. 5 is within experimental error equal to BE27.5 below which composition the hexagonal phase is formed during the $500 \mathrm{~h}$ anneal at $650^{\circ} \mathrm{C}$ in air (see above).

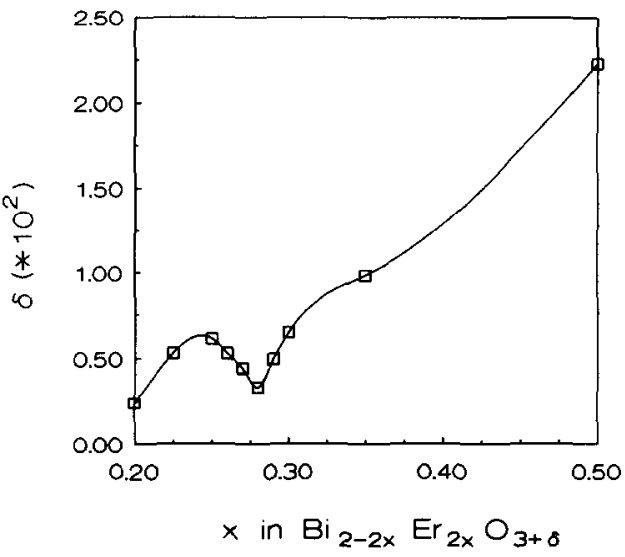

Fig.5 Compositional dependence of the departure from stoichiometry, $\delta$, of samples $\mathrm{Bi}_{2-2 x} \mathrm{Er}_{2 \mathrm{x}} \mathrm{O}_{3+\delta}$ in pure oxygen obtained from TGA data above $550^{\circ} \mathrm{C}$ $(a \rightarrow b$ in Fig. 4). The composition in nitrogen is taken as stoichiometric reference $(\delta=0)$.

Fig.6 gives the analogous quantity $M_{S} / M_{O} \times[W(d)-W(c)] / W(c)$ which expresses the total relative oxygen uptake between $550^{\circ} \mathrm{C}$ and $420^{\circ} \mathrm{C}(\mathrm{c} \rightarrow \mathrm{d}$ in Fig. 4) as a function of $x$ in $(1-x) \mathrm{Bi}_{2} \mathrm{O}_{3} \cdot \mathrm{xEr}_{2} \mathrm{O}_{3}$. In both Figs. 5 and 6 the oxygen uptake by the specimen increases with increasing erbia content.

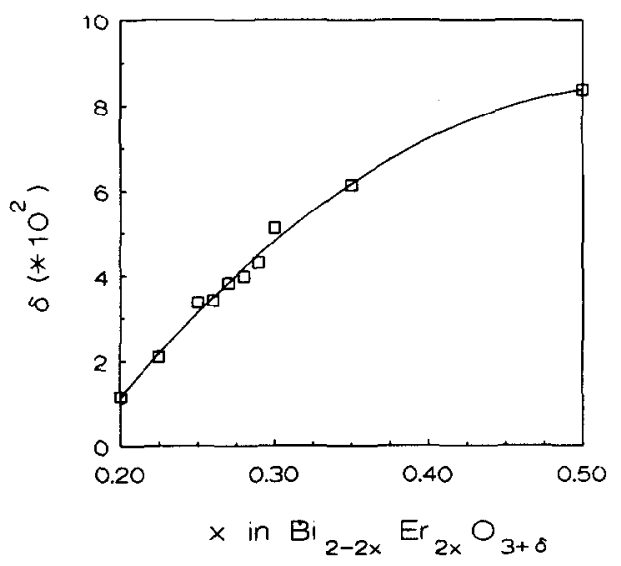

Fig.6 Compositional dependence of the total relative oxygen uptake between $550^{\circ} \mathrm{C}$ and $420^{\circ} \mathrm{C}$ in pure oxygen ( $c \rightarrow d$ in Fig. 4) by samples $\mathrm{Bi}_{2-2 x} \mathrm{Er}_{2 x} \mathrm{O}_{3+\delta}$ as measured by TGA: For sake of comparison with Fig. 5 the quantity along the vertical axis is expressed as the departure from stoichiometry, $\delta$. 
The small but measurable change in nonstoichiometry of $(1-\mathrm{x}) \mathrm{Bi}_{2} \mathrm{O}_{3} \cdot \mathrm{xEr}_{2} \mathrm{O}_{3}$ upon varying the oxygen partial pressure indicates the presence of electronic defects. Their presence is due to the equilibration of the lattice with the atmosphere involving valency changes probably of the bismuth ion. Recent oxygen permeation experiments confirm an additional electronic contribution to the conductivity. The oxygen semi-permeability flux of a sintered dense disk of BE25 of thickness $0.7 \mathrm{~mm}$ at $810^{\circ} \mathrm{C}$ is $7.8^{*} 10^{-5} \mathrm{~mol} . \mathrm{m}^{-2} \mathrm{~s}^{-1}$ in pure oxygen (versus nitrogen), which is about four orders of magnitude larger than the value observed for yttria-stabilized zirconia extrapolated to the same temperature [14]. A full discussion of these results will be reported elsewhere [15].

The nonstoichiometry of solid solutions $(1-\mathrm{x}) \mathrm{Bi}_{2} \mathrm{O}_{3} \times \mathrm{xEr}_{2} \mathrm{O}_{3}$ as deduced from Figs. 5 and 6 is influenced by the erbia content though no weight changes were observed during TGA measurements of pure erbia.

\subsection{Sample colour}

The anneal at $650^{\circ} \mathrm{C}$ in air led to a noticeable change in colour.

Prior to annealing all specimens were orange. During the anneal the colour shifted to yellow in proportion to the amount of hexagonal phase formed. No colour change was observed for compositions equal to or larger than BE27.5.

Similar colour changes were induced by changing the atmosphere to lower oxygen partial pressures. As an example, a sample of composition BE30 turns out to be orange before and after the anneal in air at $650^{\circ} \mathrm{C}$ during $500 \mathrm{~h}$. Subsequent equilibration under oxygen at $420^{\circ} \mathrm{C}$ for $20 \mathrm{~h}$ intensifies the orange colour, while shifting to yellow if equilibration is performed in nitrogen. From this it is concluded that the cubic to hexagonal phase transition leads to a change in nonstoichiometry.

The colour change during the anneal in air of samples with compositions above BE27.5 calcined during $3 \mathrm{~h}$ was taken as additional evidence of the formation of the hexagonal phase. Such a colour change for instance was not observed if the calcination time was increased to $8 \mathrm{~h}$ or $20 \mathrm{~h}$.

\section{CONCLUSIONS}

The phase study on the system (1-x) $\mathrm{Bi}_{2} \mathrm{O}_{3} \times \mathrm{xEr}_{2} \mathrm{O}_{3}$ on the basis of combined TG, DTA and X-ray measurements has provided the following information.

(a) Cubic solid solutions of (1-x) $\mathrm{Bi}_{2} \mathrm{O}_{3}, \mathrm{xEr}_{2} \mathrm{O}_{3}$ with less than 27.5 at\% of erbia are meta-stable below about $740^{\circ} \mathrm{C}$, gradually transforming to the hexagonal phase during long-term $(500 \mathrm{~h})$ annealing at $650^{\circ} \mathrm{C}$ in air. The amount of hexagonal phase present after the anneal increases in proportion to the deviation from the boundary composition BE27.5. The latter composition therefore correponds with the minimum amount of stabilizing agent needed to stabilize the cubic phase.

(b) The hexagonal to cubic phase transition apparently proceeds in two steps as established by DTA and is characterized by a change in colour, viz., from orange to yellow. It is inferred that the latter is due to a change in oxide nonstoichiometry since similar colour changes are induced in stabilized cubic phases (above composition BE27.5) by lowering the oxygen partial pressure.

(c) Varying the oxygen partial pressure leads to a small but measurable change in nonstoichiometry of samples (1-x) $\mathrm{Bi}_{2} \mathrm{O}_{3}, \mathrm{xEr}_{2} \mathrm{O}_{3}$. Above $550^{\circ} \mathrm{C}$ the oxygen uptake by samples upon changing the atmosphere from nitrogen to pure oxygen is only due to bulk processes. Above composition BE27.5 the oxygen uptake increases with erbia content whereas a minimum is observed at composition BE27.5. Below $550^{\circ} \mathrm{C}$ adsorption of oxygen on the surface of the material is partly responsible for the weight gain.

\section{REFERENCES}

[1] M.J. Verkerk and A.J. Burggraaf, J. Electrochem. Soc. 128 (1981) 75

[2] M.J. Verkerk, K. Keizer and A.J.Burggraaf, J. Appl. Electrochem. 10 (1980) 81

[3] I.C. Vinke, K. Seshan, B.A. Boukamp, K.J.de Vries and AJ. Burggraaf, Solid State Ionics 34 (1989) 235

[4] C. Wang, X. Xu and B. Li, Solid State Ionics 13 (1984) 135

[5] A.V. Joshi, S. Kulkarni, J. Nachlas, J. Diamond and N. Weber, J. Mater. Sci. 25 (1990) 1237 
[6] T. Takahashi, H. Iwahara and T. Arao, J. Appl. Electrochem. 7 (1977) 299

[7] T. Takahashi, H. Iwahara and T.Araro, J. Appl. Electrochem. 5 (1975) 187

[8] A. Watanabe and T. Kikuchi, Solid State Ionics 21 (1986) 287

[9] H. Kruidhof, K.J. de Vries and A.J. Burggraaf, Solid State Ionics 37 (1990) 21

[10] M.J. Verkerk and A.J. Burggraaf, Solid State Ionics $3 / 4$ (1981) 463

[11] H. Kruidhof, K. Seshan, G.M.H. van de Velde,
K.J. de Vries and A.J. Burggraaf, Mater. Res. Bull. 23 (1988) 371

[12] H. Kruidhof, K. Seshan, B.C. Lippens Jr., P.J. Gellings and A.J. Burggraaf, Mater. Res. Bull. 22 (1987) 1635

[13] A. Watanabe, Solid State Ionics 34 (1989) 35

[14] J. Fouletier, P. Fabry and M. Kleitz, J. Electrochem. Soc. 123 (1976) 204

[15] H.J.M. Bouwmeester, H. Kruidhof, P.J. Gellings and A.J. Burggraaf, to be published 